\title{
AVALIAÇÃO DE UM SISTEMA DE MICROPROPAGAÇÃO MASSAL DE VARIEDADES DE MANDIOCA ${ }^{1}$
}

\author{
ROBERTO PEDROSO DE OLIVEIRA ${ }^{2}$, TATIANA DA SILVA GOMES ${ }^{3}$ e ALBERTO DUARTE VILARINHOS ${ }^{4}$
}

\begin{abstract}
RESUMO - O objetivo deste trabalho foi avaliar um sistema de micropropagação massal de variedades de mandioca (Manihot esculenta Crantz). Foram utilizadas as variedades Aipim-Rosa, Aipim-Maranhão, Cangaíba, Caravela, Cravela e Pretinha. Para o isolamento dos meristemas, multiplicação e aclimatização das plântulas, empregaram-se métodos desenvolvidos na Embrapa-Centro Nacional de Pesquisa de Mandioca e Fruticultura Tropical. Após 30 dias, obteve-se desenvolvimento e formação de plântulas em 78\% dos meristemas. Independentemente da variedade e do subcultivo, a taxa média de multiplicação foi de 2,9, permitindo, assim, a obtenção de 231,2 plântulas por matriz, ao final de cinco subcultivos. Embora a porcentagem de formação de calos tenha sido elevada (22\%), não afetou negativamente a taxa de multiplicação. Praticamente não houve estiolamento, e as folhas das plântulas apresentaram desenvolvimento normal quanto a sua forma, tamanho e coloração. Os níveis médios de contaminação (7\%), perdas por outros fatores (19\%) e formação de raízes (52\%) foram satisfatórios. Houve efeito pronunciado do genótipo no desenvolvimento in vitro das plântulas. A 'Cangaíba' apresentou as maiores taxas de multiplicação, de altura das plântulas e de formação de raízes por subcultivo, sendo, em média, de 3,6, 43,7 mm e 77\%, respectivamente. As plântulas micropropagadas foram facilmente aclimatizadas.
\end{abstract}

Termos para indexação: Manihot esculenta, propagação de plantas, cultura de tecidos, cultura in vitro.

\section{EVALUATION OF A MASS MICROPROPAGATION SYSTEM OF CASSAVA VARIETIES}

\begin{abstract}
The objective of this work was to evaluate a mass micropropagation system for cassava (Manihot esculenta Crantz). Six varieties were used: Aipim-Rosa, Aipim-Maranhão, Cangaíba, Caravela, Cravela and Pretinha. Routine techniques of the Embrapa-Centro Nacional de Pesquisa de Mandioca e Fruticultura Tropical were used for meristem isolation, multiplication and plantlet acclimatization. After 30 days, $78 \%$ of meristems developed to plantlets. Independently of the variety and subculture, the average multiplication rate was 2.9, thus allowing the production of 231.2 plantlets per each initial explant, after five subcultures. Callus formation was high (22\%), but did not affect the multiplication rate. Leaves presented normal shape, size and color. The average contamination rate (7\%), losses by other factors (19\%) and root formation (52\%) were adequate. There was a strong influence of the genotype on the in vitro development of plantlets. 'Cangaíba' showed the highest multiplication rate, plantlet height and root formation per subculture, respectively of $3.6,43.7 \mathrm{~mm}$ and $77 \%$. The plantlets were easily acclimatized.
\end{abstract}

Index terms: Manihot esculenta, plant propagation, tissue culture, in vitro culture.

\footnotetext{
${ }^{1}$ Aceito para publicação em 14 de março de 2000.

${ }^{2}$ Eng. Agrôn., M.Sc., Embrapa-Centro de Pesquisa Agropecuária de Clima Temperado, Caixa Postal 403, CEP 96001-970 Pelotas, RS. E-mail: rpedroso@cena.usp.br

${ }^{3}$ Graduanda, Universidade Federal da Bahia (UFBA), Caixa Postal 82, CEP 44380-000 Cruz das Almas, BA. Bolsista do CNPq. E-mail: keuder@cnpmf.embrapa.br

${ }^{4}$ Eng. Agrôn., M.Sc., Embrapa-Centro Nacional de Pesquisa de Mandioca e Fruticultura Tropical, Caixa Postal 007, CEP 44380-000 Cruz das Almas, BA. E-mail: vila@cnpmf.embrapa.br
}

\section{INTRODUÇÃO}

A mandioca (Manihot esculenta Crantz) é originária do continente americano (Jennings, 1976) e constitui-se na principal fonte de calorias para os países da América Latina, África, Sudeste da Ásia e Oceania (Roca, 1984), sendo consumida diariamente por mais de 500 milhões de pessoas (Taylor et al., 1996). 
A produtividade brasileira de mandioca é de apenas $8 \mathrm{t} \mathrm{ha}^{-1}$, por ser cultivada, geralmente, em terras marginais de baixa fertilidade e com problemas climáticos, como a seca, além de não serem adotadas práticas agronômicas de controle de pragas e doenças (Fukuda, 1993).

A mandioca é propagada vegetativamente, a partir de estacas, chamadas de manivas. Segundo Lopez (1995), a propagação em campo é muito lenta, sendo produzidas a cada ano, sob condições adequadas de cultivo, estacas para o plantio de uma área oito vezes maior que a de sua origem. Além disso, várias doenças, principalmente as sistêmicas, podem ser transmitidas por meio de sucessivas gerações, tais como o vírus-do-mosaico-comum, vírus-do-mosaico-das-nervuras, vírus-do-mosaico-africano, vírus-colombiano sem sintomas, vírus $X$, vírus-do-mosaico-caribenho, vírus-couro-de-sapo, vírus-do-superalongamento, e também a bacteriose Xanthomonas campestris pv. manihotis e as podridões-radiculares, causadas pelos fungos Phytophthora sp., Fusarium sp., Diplodia sp. e Scytalidium sp. (Iwanaga \& Iglesias, 1994; Fukuda, 1993). Essas doenças afetam a produtividade da cultura em níveis de até $100 \%$.

A limpeza de patógenos por meio de técnicas de cultura de meristemas e a posterior micropropagação são essenciais para elevar a produtividade em regiões infestadas por viroses e bacterioses, pois disponibilizam grande quantidade de mudas em curto espaço de tempo (Roca \& Mroginski, 1991; Mabanza et al., 1994). A eficiência da cultura de meristemas depende do tipo de vírus, da variedade e do uso correto da técnica (Roca, 1984), o vigor das plantas limpas tem-se preservado por mais de quatro ciclos da cultura (Mabanza et al., 1994). Lozano et al. (1984), Roca (1984) e Mabanza et al. (1994) obtiveram aumentos de produtividade, respectivamente, de $320 \%, 70 \%$ e $100 \%$ em razão da limpeza de patógenos.

$\mathrm{Na}$ literatura são descritos protocolos para a micropropagação de mandioca (Roca, 1984; Nair et al., 1986; Smith et al., 1986), mas tratam muito superficialmente do rendimento do sistema.

Este trabalho teve por objetivo avaliar a eficiência de um sistema de micropropagação massal de variedades de mandioca.

\section{MATERIAL E MÉTODOS}

Foram utilizadas as variedades Aipim-Maranhão, Aipim-Rosa, Cangaíba, Caravela, Cravela, e Pretinha, procedentes do Estado de Sergipe. Na cultura de tecidos foram utilizados métodos desenvolvidos na Embrapa-Centro Nacional de Pesquisa de Mandioca e Fruticultura Tropical, da seguinte forma: cinco manivas $(15 \mathrm{~cm}$ de comprimento por $2,0 \mathrm{~cm}$ de diâmetro) de cada variedade, provenientes de plantas com dois anos de idade, foram plantadas em sacos de polietileno contendo $1.000 \mathrm{~cm}^{3}$ de terra vegetal esterilizada, permanecendo sob condições de telado por 30 dias. Os ponteiros $(2,0 \mathrm{~cm})$ dos brotos obtidos foram removidos e levados ao laboratório. A desinfestação foi realizada em solução contendo álcool etílico $50 \%$ por 1 minuto, e hipoclorito de cálcio $0,25 \%$, por 10 minutos. Em seguida, foram feitas três lavagens com água estéril. A extração dos meristemas $(0,4$ a $0,6 \mathrm{~mm})$ foi feita em câmara de fluxo laminar, sob estereoscópio, com auxílio de pinça e bisturi. O cultivo dos meristemas foi feito em meio contendo os macros e micronutrientes do MS (Murashige \& Skoog, 1962) suplementado com $1 \mathrm{mg} \mathrm{L}^{-1}$ de tiamina, $100 \mathrm{mg} \mathrm{L}^{-1}$ de inositol, $0,02 \mathrm{mg} \mathrm{L}^{-1}$ de ANA (ácido naftaleno acético), $0,04 \mathrm{mg} \mathrm{L}^{-1}$ de BAP (benzilaminopurina), $0,05 \mathrm{mg} \mathrm{L}^{-1}$ de $\mathrm{GA}_{3}$ (ácido giberélico), $2 \%$ de sacarose e $7 \mathrm{~g} \mathrm{~L}^{-1}$ de ágar, e pH 5,7, sob condições de temperatura de $24 \pm 2^{\circ} \mathrm{C}$, fotoperíodo de 16 horas e intensidade luminosa de 1.600 lux, por 30 dias (subcultivo 0). Foram introduzidos 20 meristemas de cada variedade em tubos de ensaio $(2,5 \mathrm{~cm}$ de diâmetro x $15 \mathrm{~cm}$ de altura) contendo $10 \mathrm{~mL}$ de meio de cultura; foram escolhidas, ao acaso, dez plântulas originárias desses meristemas, para a fase de multiplicação.

As variedades foram multiplicadas por cinco subcultivos de 30 dias (subcultivo 1 a 5) em meio de cultura composto por $35 \%$ dos macros e micronutrientes do MS, suplementado com $1 \mathrm{mg} \mathrm{L}^{-1}$ de tiamina, $100 \mathrm{mg} \mathrm{L}^{-1}$ de inositol, 0,01 $\mathrm{mg} \mathrm{L}^{-1}$ de ANA, 0,01 $\mathrm{mg} \mathrm{L}^{-1} \mathrm{de} \mathrm{GA}_{3}, 2 \%$ de sacarose e $7 \mathrm{~g} \mathrm{~L}^{-1}$ de ágar, e de $\mathrm{pH} 5,7$, nas mesmas condições de cultura acima descritas. Segmentos da parte aérea das plântulas de aproximadamente $1 \mathrm{~cm}$ contendo uma gema lateral ou apical foram utilizados como explantes nas subculturas subseqüentes. Nas subculturas 1 a 5 , foram utilizados, no máximo, 30 explantes por variedade, escolhidos ao acaso. De cada variedade e subcultivo foram avaliadas as taxas de multiplicação, a altura da parte aérea das plântulas, a formação de calos e raízes, a porcentagem de contaminação bacteriana, e a porcentagem de morte dos explantes por outros fatores. As variáveis taxa de multiplicação e altura da parte aérea das plântulas foram comparadas pelo teste de Tukey a 5\% de probabilidade, sendo transformadas em $\sqrt{x+0,5}$. As variáveis forma- 
ção de calos e de raízes, contaminação microbiana e morte de explantes foram comparadas pelo teste nãoparamétrico de Kruskal-Wallis a $5 \%$ de probabilidade.

A aclimatização foi realizada em câmara úmida, e as plântulas, transplantadas para recipientes de plástico de $200 \mathrm{~cm}^{3}$ contendo substrato à base de vermiculita, areia e terra vegetal esterilizada (1:1:1).

\section{RESULTADOS E DISCUSSÃO}

Independentemente da variedade, ocorreu desenvolvimento e formação de plântulas em $78 \%$ dos meristemas, após 30 dias de cultivo in vitro. Acedo (1994) obteve uma eficiência de $89 \%$ nessa fase, porém trabalhando com outros genótipos. Os valores obtidos refletem a eficiência dos métodos empregados.

A taxa média acumulada de multiplicação foi de 231,2 plântulas das variedades estudadas (Tabela 1), o que representa uma taxa de multiplicação de 2,9 por subcultivo de 30 dias. Acedo (1994) obteve taxas de 4 a 6 , em subcultivos de até 60 dias, e Broomes \& Lacon (1994), de 2 a 6, utilizando distintos meios de cultura. Esses autores somente computaram, em seus cálculos, as médias dos subcultivos da fase de multiplicação, e não consideraram as médias da fase de estabelecimento, em que, praticamente, apenas ocorre adaptação do material às condições de cultura in vitro. Portanto, as taxas de multiplicação obtidas permitem níveis satisfatórios para a micropropagação.
Houve efeito pronunciado do genótipo no desenvolvimento in vitro das plântulas (Tabela 1). Esse efeito já havia sido descrito em mandioca por Roca (1984). A variedade Cangaíba apresentou as maiores taxas médias de multiplicação, e foi, em muitos subcultivos, distinta, estatisticamente, das demais, pelo teste de Tukey a 5\% de probabilidade. Nos subcultivos realizados, foram obtidas 535,1 plântulas da variedade Cangaíba, valor 9,6 e 6,7 vezes maior que o obtido nas variedades Caravela e Aipim-Maranhão, respectivamente. Segundo Smith et al. (1986), existem algumas variedades que são pouco responsivas à micropropagação, e deve-se utilizar ajustes no meio de cultura, para estimular o processo. Broomes \& Lacon (1994) recomendam que sejam testadas modificações nas concentrações de sacarose, nitrogênio e reguladores de crescimento.

A altura das plântulas, a presença e intensidade de estiolamento, a forma, a coloração e tamanho das folhas, a formação de calos, o desenvolvimento de raízes, as perdas por contaminação microbiana e a eficiência de aclimatização são outros fatores importantes para a qualificação de um sistema de micropropagação.

A intensidade do desenvolvimento in vitro das plântulas quanto à sua altura foi bastante variada, sendo evidenciada pelo alto coeficiente de variação, em média, de 25,3\% (Tabela 2). Esse tipo de resultado é bastante comum em trabalhos de cultura de tecidos. A presença de plântulas pouco desenvolvidas foi muito mais freqüente que a de estioladas. Entre

TABELA 1. Taxa média de multiplicação por subcultivo de variedades de mandioca (Manihot esculenta Crantz) durante a micropropagação. Cruz das Almas, 1998'.

\begin{tabular}{|c|c|c|c|c|c|c|c|}
\hline \multirow[t]{2}{*}{ Variedade } & \multicolumn{6}{|c|}{ Subcultivo } & \multirow{2}{*}{$\begin{array}{c}\text { Taxa de } \\
\text { multiplicação } \\
\text { acumulada }\end{array}$} \\
\hline & 0 & 1 & 2 & 3 & 4 & 5 & \\
\hline Aipim-Rosa & $1,0 \mathrm{a}$ & $1,0 \mathrm{a}$ & $3,8 \mathrm{ab}$ & $4,0 \mathrm{~b}$ & $2,6 \mathrm{bc}$ & $4,5 \mathrm{ab}$ & 177,8 \\
\hline Aipim-Maranhão & $1,0 \mathrm{a}$ & $1,0 \mathrm{a}$ & $3,3 \mathrm{~b}$ & $4,4 a b$ & $2,3 \mathrm{bc}$ & $2,4 \mathrm{c}$ & 80,2 \\
\hline Cangaíba & $1,0 \mathrm{a}$ & $1,0 \mathrm{a}$ & $5,2 \mathrm{a}$ & $6,0 \mathrm{ab}$ & $3,5 \mathrm{ab}$ & $4,9 a$ & 535,1 \\
\hline Caravela & $1,0 \mathrm{a}$ & $1,0 \mathrm{a}$ & $3,6 b$ & $4,1 \mathrm{ab}$ & $1,4 \mathrm{c}$ & $2,7 \mathrm{c}$ & 55,8 \\
\hline Cravela & $1,0 \mathrm{a}$ & $1,0 \mathrm{a}$ & $4,4 \mathrm{ab}$ & $5,9 \mathrm{ab}$ & $3,6 a b$ & $3,0 \mathrm{bc}$ & 280,4 \\
\hline Pretinha & $1,0 \mathrm{a}$ & $1,0 \mathrm{a}$ & $4,3 \mathrm{ab}$ & $6,1 \mathrm{a}$ & $4,1 \mathrm{a}$ & $2,4 \mathrm{c}$ & 258,1 \\
\hline Média & 1,0 & 1,0 & 4,1 & 5,1 & 2,9 & 3,5 & 231,2 \\
\hline CV (\%) & 0,0 & 0,0 & 9,9 & 11,9 & 11,4 & 8,4 & \\
\hline
\end{tabular}

1 Médias seguidas de mesma letra, na coluna, não diferem entre si pelo teste de Tukey, a 5\% de probabilidade; na análise estatística, os valores foram transformados em $\sqrt{\mathrm{x}+0,5}$. 
as variedades estudadas, nenhuma mostrou possuir dominância apical acentuada, conforme descrevem Smith et al. (1986). A média de altura das plântulas das diferentes variedades foi de apenas $24,2 \mathrm{~mm}$. Possivelmente, com o aumento no período entre os subcultivos poder-se-á maximizar a utilização dos frascos e do meio de cultura. A variedade Cangaíba apresentou as maiores médias de altura das plântulas ao longo dos subcultivos, inclusive com diferenças significativas.

Independentemente da variedade, houve desenvolvimento normal das folhas das plântulas quanto a sua forma, tamanho e coloração. Conseqüentemente, não foram identificadas variantes somaclonais, in vitro, quanto às características morfologicamente visíveis.

Segundo Roca (1984), a formação de calos em sistemas de micropropagação a partir de gemas laterais e apicais com posterior organogênese ou embriogênese é indesejável, pois pode promover o aparecimento de variantes somaclonais. Na média geral, $22 \%$ dos explantes apresentaram formação de calo (Tabela 3), o que pode ser considerado um nível elevado. Roca (1984) e Guo \& Liu (1994) associam a formação de calos a níveis elevados de BAP (maiores que $0,1 \mathrm{mg} \mathrm{L}^{-1}$ ) no meio de cultura, e destacam que o processo inibe o crescimento das plântulas. Como o BAP somente foi utilizado na fase de estabelecimento in vitro dos explantes e, mesmo assim, na concentração de $0,04 \mathrm{mg} \mathrm{L}^{-1}$, a formação de calos observada deve ser atribuída a desequilíbrios fisiológicos causados por outros fatores.
Nas variedades estudadas, as maiores porcentagens de formação de calos ocorreram nos subcultivos 1 e 2, com uma média de $58 \%$ e $50 \%$, respectivamente (Tabela 3). A freqüente formação de calos nessa fase é comum, e deve-se à adaptação dos explantes às condições de cultura in vitro. Em todos os casos, os calos formaram-se apenas na base dos explantes, mostrando-se pouco friáveis, de coloração amareloesbranquiçada, e não foram organogênicos ou embriogênicos.

Ao contrário dos sistemas de micropropagação utilizados nas espécies de abacaxizeiro e bananeira (Oliveira \& Silva, 1997), a presença de raízes nas plântulas de mandioca, em quantidade equilibrada com o desenvolvimento da parte aérea, é benéfica à multiplicação, por promover maior absorção de nutrientes e consequiente produção de gemas, que servirão de explantes para os subcultivos subseqüentes. A variedade Cangaíba apresentou a maior porcentagem média de plântulas com raízes $(77 \%)$ nos subcultivos realizados, e, conseqüentemente, a maior taxa de multiplicação acumulada. Acedo (1994) e Broomes \& Lacon (1994) obtiveram, respectivamente, $61 \%$ e $80 \%$ de formação de raízes, com taxas satisfatórias de multiplicação.

A porcentagem média de contaminação obtida nas variedades, nos subcultivos realizados, foi de $7 \%$ (Tabela 4). Esses níveis são semelhantes aos obtidos em experimentos deste tipo em outras espécies (Oliveira \& Silva, 1997). As variedades Aipim-Rosa e Cangaíba apresentaram as maiores porcentagens de contaminação, respectivamente de $15 \%$ e $10 \%$. Como

TABELA 2. Altura média da parte aérea de plântulas $(\mathrm{mm})$ por subcultivo de variedades de mandioca (Manihot esculenta Crantz) durante a micropropagação. Cruz das Almas, 19981.

\begin{tabular}{lccccccc}
\hline Variedade & \multicolumn{7}{c}{ Subcultivo } \\
\cline { 2 - 7 } & 0 & 1 & 2 & 3 & 4 & 5 & Média \\
\hline Aipim-Rosa & $7,9 \mathrm{~b}$ & $8,6 \mathrm{c}$ & $12,0 \mathrm{a}$ & $29,7 \mathrm{~b}$ & $74,7 \mathrm{ab}$ & $25,7 \mathrm{ab}$ & 26,4 \\
Aipim-Maranhão & $13,1 \mathrm{ab}$ & $15,3 \mathrm{ab}$ & $10,7 \mathrm{a}$ & $20,4 \mathrm{~b}$ & $42,3 \mathrm{bc}$ & $16,5 \mathrm{bc}$ & 19,7 \\
Cangaíba & $17,1 \mathrm{a}$ & $17,7 \mathrm{a}$ & $16,7 \mathrm{a}$ & $63,7 \mathrm{a}$ & $117,1 \mathrm{a}$ & $29,7 \mathrm{a}$ & 43,7 \\
Caravela & $12,2 \mathrm{ab}$ & $12,7 \mathrm{abc}$ & $13,6 \mathrm{a}$ & $17,4 \mathrm{~b}$ & $37,2 \mathrm{bc}$ & $20,3 \mathrm{ac}$ & 18,9 \\
Cravela & $8,5 \mathrm{ab}$ & $11,3 \mathrm{bc}$ & $13,1 \mathrm{a}$ & $17,5 \mathrm{~b}$ & $38,4 \mathrm{bc}$ & $24,5 \mathrm{a}$ & 18,9 \\
Pretinha & $12,4 \mathrm{ab}$ & $15,6 \mathrm{ab}$ & $18,3 \mathrm{a}$ & $20,4 \mathrm{~b}$ & $26,3 \mathrm{c}$ & $12,2 \mathrm{c}$ & 17,5 \\
\hline Média & 11,9 & 13,5 & 14,1 & 28,1 & 56,0 & 21,5 & 24,2 \\
CV $(\%)$ & 26,2 & 13,8 & 21,3 & 32,8 & 33,5 & 24,2 & 25,3 \\
\hline
\end{tabular}

1 Médias seguidas de mesma letra, na coluna, não diferem entre si pelo teste de Tukey, a 5\% de probabilidade; na análise estatística, os valores foram transformados em $\sqrt{\mathrm{x}+0,5}$. 
as contaminações foram causadas por fungos e bactérias aparentemente distintos, pode-se considerar que as diferenças obtidas foram ao acaso. No subcultivo 0 , ocorreram as maiores taxas de contaminação: em média, $15 \%$. Este valor, considerado normal para a fase de estabelecimento in vitro, revela adequação dos métodos utilizados para a assepsia e desinfestação dos explantes.

Os explantes podem morrer por uma série de causas fisiológicas, como a contaminação microbiana. Nas variedades estudadas, houve, em média, $19 \%$ de perda dos explantes por alguma dessas causas (Tabela 4). Adequações na composição dos meios de cultura e na manipulação dos explantes podem ser realizadas principalmente nas variedades em que houve maiores perdas, como, por exemplo, na Pretinha $(34 \%)$. Inferências sobre as causas fisiológicas envolvidas requerem estudos específicos.
A eficiência na aclimatização das plântulas foi em torno de $92 \%$; não houve diferenças relevantes entre as variedades. Broomes \& Lacon (1994) e Guo \& Liu (1994) obtiveram porcentagens de sobrevivência de $82 \%$ e $95 \%$, respectivamente, também não encontrando dificuldades para aclimatizar as mudas.

O potencial para a micropropagação de mandioca é grande, principalmente nos casos de multiplicação de materiais livres de patógenos (Mabanza et al., 1994). O sistema de micropropagação utilizado, avaliado em razão de diferentes variáveis, foi satisfatório, notadamente na variedade Cangaíba. Desta forma, pode ser utilizado para produção em maior escala. Segundo Roca (1984), os explantes gemas laterais e apicais de mandioca são bastante estáveis in vitro, e por isso, acredita-se que possa ser realizado um número de subcultivos bastante superior ao empregado neste trabalho, viabilizando ainda mais a

TABELA 3. Porcentagem de formação de calos e raízes de variedades de mandioca (Manihot esculenta Crantz) por subcultivo (SC) durante a micropropagação. Cruz das Almas, 19981.

\begin{tabular}{|c|c|c|c|c|c|c|c|c|c|c|c|c|c|c|}
\hline \multirow[t]{2}{*}{ Variedade } & \multicolumn{2}{|c|}{ SC 0} & \multicolumn{2}{|c|}{ SC 1} & \multicolumn{2}{|c|}{ SC 2} & \multicolumn{2}{|c|}{$\mathrm{SC} 3$} & \multicolumn{2}{|c|}{$\mathrm{SC} 4$} & \multicolumn{2}{|c|}{ SC 5} & \multicolumn{2}{|c|}{ Média } \\
\hline & Calos & Raízes & Calos & Raízes & Calos & Raízes & Calos & Raízes & Calos & Raízes & Calos & Raízes & Calos & Raízes \\
\hline Aipim-Rosa & $0 \mathrm{a}$ & $0 \mathrm{~b}$ & $60 \mathrm{a}$ & $30 \mathrm{a}$ & $40 \mathrm{a}$ & $20 \mathrm{a}$ & $10 \mathrm{a}$ & $70 \mathrm{a}$ & $0 \mathrm{a}$ & $90 \mathrm{a}$ & $8 \mathrm{a}$ & $74 a$ & 20 & 47 \\
\hline Aipim-Maranhão & $0 \mathrm{a}$ & $50 \mathrm{a}$ & $70 \mathrm{a}$ & $0 \mathrm{a}$ & $80 \mathrm{a}$ & $20 \mathrm{a}$ & $10 \mathrm{a}$ & $80 \mathrm{a}$ & $0 \mathrm{a}$ & $100 \mathrm{a}$ & $13 a$ & $45 \mathrm{a}$ & 29 & 49 \\
\hline Cangaíba & $0 \mathrm{a}$ & $90 \mathrm{a}$ & $40 \mathrm{a}$ & $50 \mathrm{a}$ & $40 \mathrm{a}$ & $50 \mathrm{a}$ & $0 \mathrm{a}$ & $90 \mathrm{a}$ & $0 \mathrm{a}$ & $100 \mathrm{a}$ & $1 \mathrm{a}$ & $81 \mathrm{a}$ & 14 & 77 \\
\hline Caravela & $10 \mathrm{a}$ & $50 \mathrm{a}$ & $50 \mathrm{a}$ & $50 \mathrm{a}$ & $60 \mathrm{a}$ & $30 \mathrm{a}$ & $0 \mathrm{a}$ & $90 \mathrm{a}$ & $0 \mathrm{a}$ & $60 \mathrm{a}$ & $14 \mathrm{a}$ & $6 \mathrm{~b}$ & 22 & 48 \\
\hline Cravela & $30 \mathrm{a}$ & $10 \mathrm{~b}$ & $100 \mathrm{a}$ & $0 \mathrm{a}$ & $60 \mathrm{a}$ & $0 \mathrm{a}$ & $10 \mathrm{a}$ & $90 \mathrm{a}$ & $10 \mathrm{a}$ & $90 \mathrm{a}$ & $3 a$ & $60 \mathrm{a}$ & 36 & 42 \\
\hline Pretinha & $0 \mathrm{a}$ & $40 \mathrm{a}$ & $30 \mathrm{a}$ & $70 \mathrm{a}$ & $20 \mathrm{a}$ & $20 \mathrm{a}$ & $20 \mathrm{a}$ & $50 \mathrm{a}$ & $0 \mathrm{a}$ & $60 \mathrm{a}$ & $2 \mathrm{a}$ & $54 \mathrm{a}$ & 12 & 49 \\
\hline Média & 7 & 40 & 58 & 33 & 50 & 23 & 8 & 78 & 2 & 83 & 7 & 53 & 22 & 52 \\
\hline $\mathrm{CV}(\%)$ & 31 & 41 & 26 & 35 & 24 & 31 & 10 & 23 & 8 & 15 & 28 & 16 & 23 & 14 \\
\hline
\end{tabular}

1 Médias seguidas pela mesma letra, na coluna, não diferem entre si pelo teste não-paramétrico de Kruskal-Wallis, a 5\% de probabilidade.

TABELA 4. Porcentagem de perda de explantes por subcultivo (SC) de variedades de mandioca (Manihot esculenta Crantz) por contaminação microbiana (CM) e por outros fatores (OF) durante a micropropagação. Cruz das Almas, 19981.

\begin{tabular}{|c|c|c|c|c|c|c|c|c|c|c|c|c|c|c|}
\hline \multirow[t]{2}{*}{ Variedade } & \multicolumn{2}{|c|}{ SC 0} & \multicolumn{2}{|c|}{$\mathrm{SC} 1$} & \multicolumn{2}{|c|}{ SC 2} & \multicolumn{2}{|c|}{ SC 3} & \multicolumn{2}{|c|}{$\mathrm{SC} 4$} & \multicolumn{2}{|c|}{ SC 5} & \multicolumn{2}{|c|}{ Média } \\
\hline & $\mathrm{CM}$ & $\mathrm{OF}$ & $\mathrm{CM}$ & $\mathrm{OF}$ & $\mathrm{CM}$ & $\mathrm{OF}$ & $\mathrm{CM}$ & $\mathrm{OF}$ & $\mathrm{CM}$ & $\mathrm{OF}$ & $\mathrm{CM}$ & $\mathrm{OF}$ & $\mathrm{CM}$ & $\mathrm{OF}$ \\
\hline Aipim-Rosa & $30 a$ & $10 \mathrm{a}$ & $0 \mathrm{a}$ & $10 \mathrm{a}$ & $0 \mathrm{a}$ & $0 \mathrm{a}$ & $30 \mathrm{a}$ & $30 a$ & $30 a$ & $20 a$ & $0 \mathrm{a}$ & $11 \mathrm{a}$ & 15 & 14 \\
\hline Aipim-Maranhão & $10 \mathrm{a}$ & $10 \mathrm{a}$ & $10 \mathrm{a}$ & $10 \mathrm{a}$ & $0 \mathrm{a}$ & $0 \mathrm{a}$ & $10 \mathrm{a}$ & $40 a$ & $10 \mathrm{a}$ & $40 a$ & $0 \mathrm{a}$ & $21 \mathrm{a}$ & 7 & 20 \\
\hline Cangaíba & $30 a$ & $20 a$ & $0 \mathrm{a}$ & $0 \mathrm{a}$ & $10 \mathrm{a}$ & $20 \mathrm{a}$ & $10 \mathrm{a}$ & $20 a$ & $10 \mathrm{a}$ & $20 a$ & $0 \mathrm{a}$ & $12 \mathrm{a}$ & 10 & 15 \\
\hline Caravela & $0 \mathrm{a}$ & $30 a$ & $0 \mathrm{a}$ & $0 \mathrm{a}$ & $10 \mathrm{a}$ & $0 \mathrm{a}$ & $10 \mathrm{a}$ & $30 a$ & $10 \mathrm{a}$ & $50 \mathrm{a}$ & $11 \mathrm{a}$ & $17 \mathrm{a}$ & 7 & 21 \\
\hline Cravela & $20 a$ & $10 \mathrm{a}$ & $0 \mathrm{a}$ & $0 \mathrm{a}$ & $0 \mathrm{a}$ & $10 \mathrm{a}$ & $0 \mathrm{a}$ & $20 \mathrm{a}$ & $0 \mathrm{a}$ & $20 \mathrm{a}$ & $8 \mathrm{a}$ & $14 \mathrm{a}$ & 5 & 12 \\
\hline Pretinha & $0 \mathrm{a}$ & $50 \mathrm{a}$ & $0 \mathrm{a}$ & $40 a$ & $0 \mathrm{a}$ & $20 \mathrm{a}$ & $0 \mathrm{a}$ & $30 a$ & $0 \mathrm{a}$ & $50 \mathrm{a}$ & $4 a$ & $15 \mathrm{a}$ & 0 & 34 \\
\hline Média & 15 & 22 & 2 & 10 & 3 & 8 & 10 & 28 & 10 & 33 & 4 & 15 & 7 & 19 \\
\hline $\mathrm{CV}(\%)$ & 43 & 41 & 8 & 26 & 9 & 21 & 13 & 30 & 26 & 31 & 23 & 29 & 25 & 30 \\
\hline
\end{tabular}

1 Médias seguidas pela mesma letra, na coluna, não diferem entre si pelo teste não-paramétrico de Kruskal-Wallis, a 5\% de probabilidade. 
micropropagação comercial da cultura. No entanto, a caracterização de variantes somaclonais e a definição de um número máximo seguro de repicagens precisam ser melhor estudadas.

\section{CONCLUSÕES}

1. O sistema de micropropagação avaliado proporciona níveis satisfatórios de multiplicação de variedades de mandioca.

2. Existe efeito pronunciado do genótipo no desenvolvimento in vitro das plântulas.

3. A variedade Cangaíba apresenta o melhor desempenho para propagação in vitro.

4. As plântulas micropropagadas de mandioca são facilmente aclimatizadas.

\section{REFERÊNCIAS}

ACEDO, V.Z. Meristem culture and in vitro maintenance of Philippine cassava. In: INTERNATIONAL SCIENTIFIC MEETING ON CASSAVA BIOTECHNOLOGY NETWORK, 2., 1994, Bogor. Proceedings. Bogor : Cassava Biotechnology Network, 1994. p.202-209.

BROOMES, V.F.; LACON, R. Influence of medium components on hardening of cassava after micropropagation in liquid nutrient medium. In: INTERNATIONAL SCIENTIFIC MEETING ON CASSAVA BIOTECHNOLOGY NETWORK, 2., Bogor, 1994. Proceedings. Bogor : Cassava Biotechnology Network, 1994. p.210-219.

FUKUDA, C. Doenças da mandioca. In: EMBRAPA. Centro Nacional de Mandioca e Fruticultura (Cruz das Almas, BA). Instruções práticas para o cultivo da mandioca. Cruz das Almas, 1993. p.53-56.

GUO, J.Y.; LIU, Y.Q. Rapid propagation of cassava by tissue culture and its application in rural districts in China. In: INTERNATIONAL SCIENTIFIC MEETING ON CASSAVA BIOTECHNOLOGY NETWORK, 2., Bogor, 1994. Proceedings. Bogor : Cassava Biotechnology Network, 1994. p.183-189.

IWANAGA, M.; IGLESIAS, C. Cassava genetic resources management at CIAT. In: INTERNATIONAL NETWORK FOR CASSAVA GENETIC RESOURCES, 1., 1992, Cali. Proceedings. Rome : International Plant Resources Institute, 1994. p.77-86.
JENNINGS, D.L. Cassava, Manihot esculenta (Euphorbiaceae). In: SIMMONDS, N.W. (Ed.). Evolution of crop plants. London : Longman, 1976. p.81-84.

LOPEZ, J.M. Producción comercial de semilla de yuca. Yuca Boletin Informativo, Cali, v.19, n.2, p.1-2, 1995.

LOZANO, J.C.; PINEDA, B.; JAYASINGHE, U. Effect of cutting quality on cassava. In: SYMPOSIUM OF THE INTERNATIONAL SOCIETY FOR TROPICAL ROOT CROPS, 6., 1983, Lima. Proceedings. Lima : International Potato Center, 1984. p.433-439.

MABANZA, J.; RODRIGUEZ-ANDRIYAMASI, A.V.; MAHOUKA, J.; BOUMBA, B. Evaluation of cleaned cassava varieties in Congo. In: INTERNATIONAL SCIENTIFIC MEETING ON CASSAVA BIOTECHNOLOGY NETWORK, 2., 1994, Bogor. Proceedings. Bogor : Cassava Biotechnology Network, 1994. p.194-201.

MURASHIGE, T.; SKOOG, F. A revised medium for rapid growth and bioassays with tobacco tissue cultures. Physiologia Plantarum, Copenhagen, v.15, p.473-497, 1962.

NAIR, G.M.; PRABHAKAR, M.; NAIR, N.G.; GHOSH, S.P. Production of cassava planting material in India. In: GLOBAL WORKSHOP ON ROOT AND TUBER CROPS PROPAGATION, 1983, Cali. Proceedings. Cali : CIAT, 1986. p.187-192.

OLIVEIRA, R.P.; SILVA, S.O. Micropropagação massal em bananeira. Pesquisa Agropecuária Brasileira, Brasília, v.32, n.4, p.415-420, abr. 1997.

ROCA, W.M. Cassava. In: SHARP, W.R.; EVANS, D.A.; AMMIRATO, P.V.; YAMADA, Y. (Ed.). Handbook of plant cell culture: crop species. New York : Mcmillan, 1984. p.269-301.

ROCA, W.M.; MROGINSKI, L.A. Cultivo de tejidos en la agricultura: fundamentos y aplicaciones. Cali : CIAT, 1991. 969p.

SMITH, M.K.; BIGGS, B.J.; SCOTT, K.J. In vitro propagation of cassava (Manihot esculenta Crantz). Plant Cell, Tissue and Organ Culture, Dordrecht, v.6, p.221-228, 1986.

TAYLOR, N.J.; EDWARDS, M.; KIERNAN, R.J.; DAVEY, C.D.M.; BLAKESLEY, D.; HENSHAW, G.G. Development of friable embryogenic callus and embryogenic suspension culture systems in cassava (Manihot esculenta Crantz). Nature Biotechnology, New York, v.14, p.726-730, 1996. 